\title{
Characterization of $\mathrm{CeO}_{2}, \mathrm{ZrO}_{2}$, and $\mathrm{CeZrO}_{2}$ Crystals on CNT
}

\author{
K. MATUS ${ }^{a, *}$ A. EAMACZ ${ }^{b}$ AND B. LISZKA ${ }^{c}$
}

${ }^{a}$ Institute of Engineering Materials and Biomaterials, Silesian University of Technology, Gliwice, Poland

${ }^{b}$ Department of Chemistry and Technology of Fuels, Wroclaw University of Science and Technology,

Gdańska 7/9, 50-344 Wrocław, Poland

${ }^{c}$ Centre of Polymer and Carbon Materials, Polish Academy of Sciences,

M. Curie-Skłodowskiej 34, 41819 Zabrze, Poland

Carbon nanotubes are increasingly being used as a support for catalyst particles. Carbon nanotubes are also used for filtering and reduction, their widespread use due to the high surface area which allows for attachment to the surface of carbon nanotubes a large amount of metallic (Ni, Fe, Pt, etc.) or oxide particles, serving as catalysts. The use of ceria-zirconia mixed oxide deposited on the surface of the nanotubes has not yet been sufficiently examined. Scanning transmission electron microscope with high-angle annular dark-field imaging and high-resolution transmission electron microscopy imaging were used as primary research techniques. Conducted research using high-angle annular dark-field imaging allows determining that catalyst particles have a regular shape which is the best from the standpoint of catalysis. Using a fast Fourier transform and diffraction pattern has identified the catalyst particles as $\mathrm{CeZrO}_{2}$.

DOI: 10.12693/APhysPolA.130.966

PACS/topics: $68.55 . \mathrm{Nq}, 81.30 . \mathrm{Mh}, 68.37 . \mathrm{Ma}, 61.48 . \mathrm{De}, 82.45 . \mathrm{Jn}$

\section{Introduction}

The importance of nanomaterials is steadily increasing, the main field of their application is environmental protection, medicine, energy. Best research technique to characterise nanomaterials is transmission electron microscopy (TEM). Research technique particularly useful for materials especially when the elements varies $Z$ number widely is a scanning transmission electron microscopy (STEM). The difference in contrast (thanks to different $Z$ number) between the catalyst particles and support is unambiguous. Carbon nanotubes (CNT) are increasingly being used as a support for catalyst particles, for catalysts used in various reactions [1-3]. CNT are also used for filtering and reduction, their widespread use due to the high surface area that allows for attachment to the surface of carbon nanotubes a large amount of metallic $(\mathrm{Ni}, \mathrm{Fe}, \mathrm{Pt}$, etc.) or oxide particles [2,3]. The use of nickel particles as a catalyst on the surface of the CNT is common while only some studies on synthesis and catalytic activity of ceria $\left(\mathrm{CeO}_{2}\right)$ containing hybrid CNTbased materials have been so far conducted [4-6]. Deposition of ceria-zirconia mixed oxide $\left(\mathrm{CeZrO}_{2}\right)$ on carbon nanotubes, which reveals better catalytic properties than $\mathrm{CeO}_{2}$, has not been reported yet. Even if the shape, size, and distribution of the nanoparticles play a predominant function for catalytic activity, the structure, and properties of the support is also a vital factor. The aim of this paper is phase analysis of $\mathrm{CeO}_{2}, \mathrm{ZrO}_{2}$ and $\mathrm{CeZrO}_{2}$ crystals deposited on CNT.

\section{Material}

Among different active phases that can be deposited on CNTs, we have chosen $\mathrm{Ni}$ and ceria-zirconia oxide

\footnotetext{
*corresponding author; e-mail: krzysztof.matus@polsl.pl
}

and studied such hybrid materials in water gas shift (WGS) reaction. The investigation has been carried out on hybrid material $\mathrm{CeZrO}_{2} / \mathrm{CNT}$, that has not yet been reported in the literature. The carbon nanotubes are functionalized and dispersed in acetone, and then there was added to the nanotubes high surface area $\mathrm{CeZrO}_{2}$ catalyst (obtained by impregnation of $\mathrm{CeZrO}_{2}$ with $\left.\mathrm{Ni}\left(\mathrm{NO}_{3}\right)_{2} \cdot 6 \mathrm{H}_{2} \mathrm{O}\right)$, by this method the $\mathrm{CeZrO}_{2} / \mathrm{CNT}$ were obtained. Next, the material was dried and calcined at $700^{\circ} \mathrm{C}$ for $2 \mathrm{~h}$ under flowing $\mathrm{Ar}$.

\section{Method}

The samples for transmission electron microscopy investigations were prepared by dispersing $\mathrm{CeZrO}_{2} / \mathrm{CNT}$ in ethanol, placing in an ultrasonic bath, then putting droplets onto $3 \mathrm{~mm}$ copper grids coated with amorphous carbon film and drying in air at room temperature. Electron microscopy observations were done on a probe Cscorrected S/TEM Titan 80-300 FEI microscope equipped with EDAX EDS (energy dispersive X-ray spectroscopy) detector. A $300 \mathrm{kV}$ electron beam with a convergence semi-angle of 27 and $17 \mathrm{mrad}$ was used. The images were recorded in STEM-mode, using the high-angle annular dark field (HAADF) detector. The HAADF images are formed by recording the intensity of scattered electrons as a function of beam incident position on the sample surface. High-angle annular dark field collects electrons scattered at a large angle. High-angle scattering results from the interaction of electrons with the potential field created by the atomic nuclei and this scattering is proportional to the square of the electric charge of the nucleus. HAADF detector allows to indicate the contrast between columns of atoms of differentiated elements. EDS analysis was performed using large beam current and convergence semi-angle of $34 \mathrm{mrad}$ to amplify the signal. For crystallographic simulation EjeZ [7, 8] software was used. 


\section{Results}

Analysed oxides have a similar morphology, especially $\mathrm{ZrO}_{2}$ and $\mathrm{CeZrO}_{2}$ phase with very small variations in the unit cell parameters (Table I). Such small difference stems from the fact that the cerium atoms replaced atoms of zirconia which causes creation of mixed oxide. Simulations of unit cells are shown in Fig. 1. For the identification of oxides phases fast Fourier transform (FFT), computer simulations of the diffraction pattern, and EDS were used.

TABLE I

Crystallographic data of investigated oxides [9].

$\alpha=\beta=\gamma=90^{\circ}$.

\begin{tabular}{|c|c|c|c|c|c|}
\hline \multirow[t]{2}{*}{ Phase } & \multirow{2}{*}{$\begin{array}{l}\text { Database } \\
\text { reference }\end{array}$} & \multirow{2}{*}{$\begin{array}{l}\text { Space } \\
\text { group }\end{array}$} & $a$ & $b$ & $c$ \\
\hline & & & \multicolumn{3}{|c|}{$[\AA]$} \\
\hline $\mathrm{CeO}_{2}$ & 4343161 & $F m-3 m$ & 5.41 & 5.41 & 5.41 \\
\hline $\mathrm{ZrO}_{2}$ & 1525705 & $P 42 / n m c: 1$ & 3.58 & 3.58 & 5.16 \\
\hline $\mathrm{CeZrO}_{2}$ & 2102841 & $P 42 / n m c: 1$ & 3.74 & 3.74 & 5.34 \\
\hline
\end{tabular}
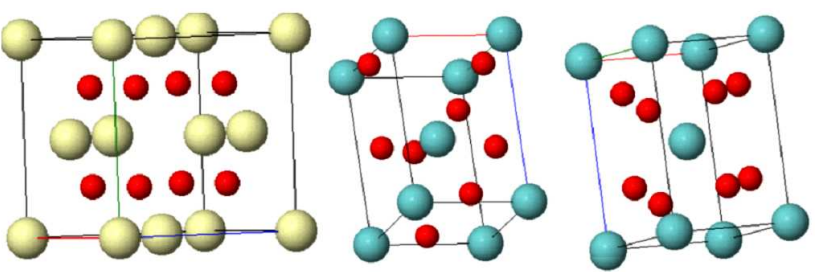

Fig. 1. Crystal structure of $\mathrm{CeO}_{2}, \mathrm{ZrO}_{2}, \mathrm{CeZrO}_{2}$.

The oxides deposited on carbon nanotubes are characterised by a fairly high homogeneity and even distribution on the surface (Fig. 2). As shown in Fig. 2 oxides deposited on the carbon nanotubes are characterised by nanometric size (the average crystal size was estimated as about $5-8 \mathrm{~nm}$ ) and the oval-like shape elongated in a direction parallel to the nanotubes wall on which the oxide had grown. Analysed oxides have a good connection with nanotubes, which favors their application potential.
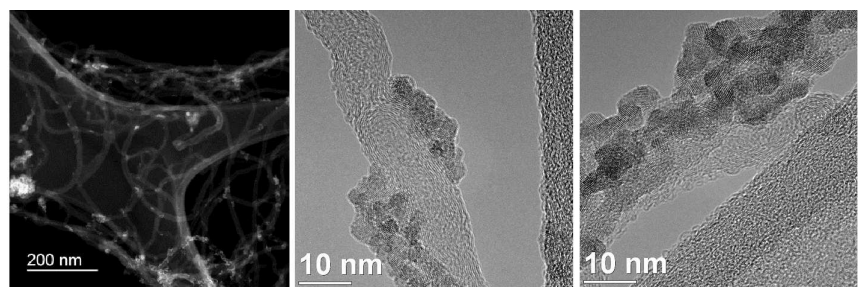

Fig. 2. HAADF image of carbon nanotubes covered by oxides (left) and HRTEM image of oxides on CNT (middle, right).

To observe the crystals STEM was used. The crystals are of the spherical shape. Based on the analysis of the 60 crystals it was determined that the average crystal size is $4 \mathrm{~nm}$. An example is shown in Fig. 3 (left). Fourier transformation of obtained image is inserted on the left side. The distances and angles between reflections on the
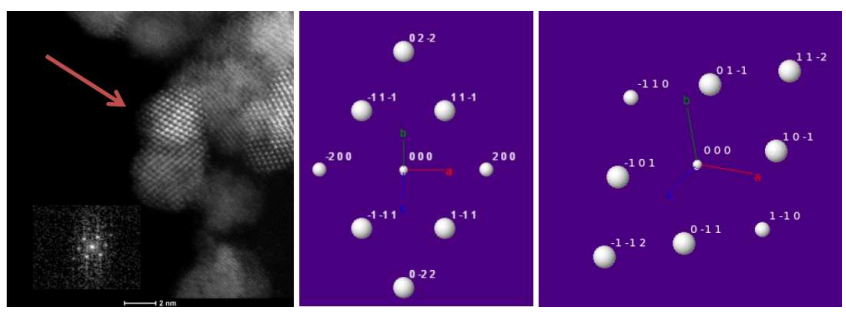

Fig. 3. HAADF image of analysed oxide with inserted FFT (left), simulation of diffraction pattern of $\mathrm{CeO}_{2}$ in direction [011] (middle), and simulation of the diffraction pattern of $\mathrm{CeZrO}_{2}$ in the direction [111] (right).

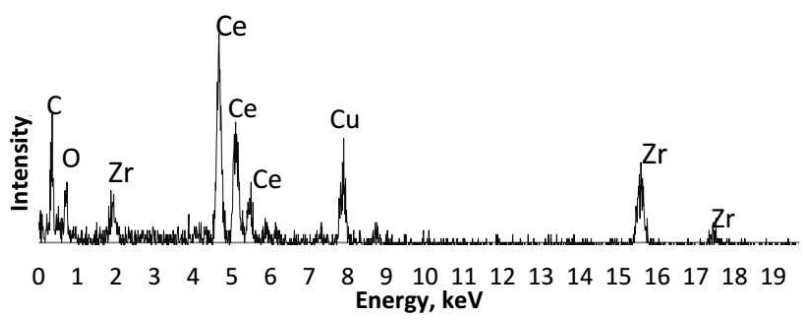

Fig. 4. EDS spectrum of oxide from Fig. 3 (left). The scan volume was approximately $1-10 \mathrm{~nm}^{3}$.

FFT can be measured and next compared with the computer simulation of diffraction patterns obtained for each phase in any selected direction. In the analysed example the distance were $0.332 \mathrm{~nm}$ and $0.276 \mathrm{~nm}$, while the angle between selected reflections on the diffraction pattern was $56.31^{\circ}$. Using software EjeZ phase [8] we identified three directions that meet these requirements (the uncertainty in the distances was assumed at $0.1 \AA$, the angle of $3^{\circ}$ ). For each phase in any selected direction the computer simulation of diffraction patterns were obtained and compared with analysed FFT. In that case two potential solutions can be indicated: first of them was $\mathrm{CeO}_{2}$ in the direction of [011] (Fig. 3 (middle)) and second was $\mathrm{CeZrO}_{2}$ in the direction of [111] (Fig. 3 (right)).

Identified elements in analysed oxide are shown in Fig. 4, the zirconium content allowed to reject $\mathrm{CeO}_{2}$ from the analysis. Comparison of the results of diffraction, computer simulations, and chemical composition al-
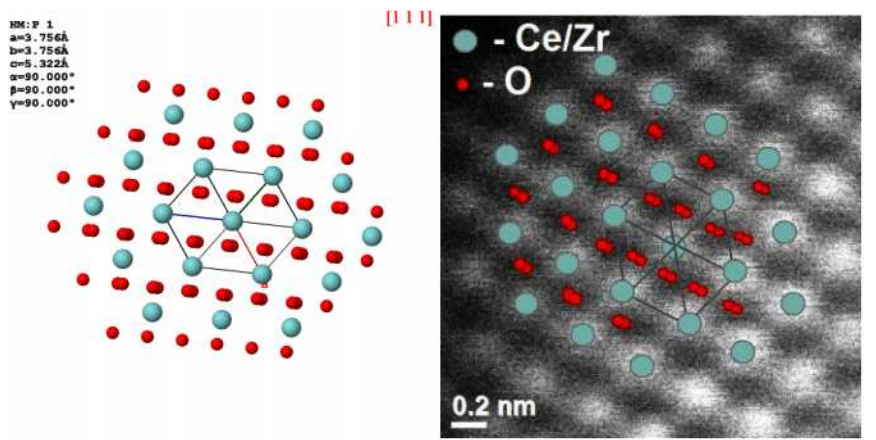

Fig. 5. Simulation of $\mathrm{CeZrO}_{2}$ in the direction [111] (left). Fitting of $\mathrm{CeZrO}_{2}$ simulation to the HAADF image (right). 


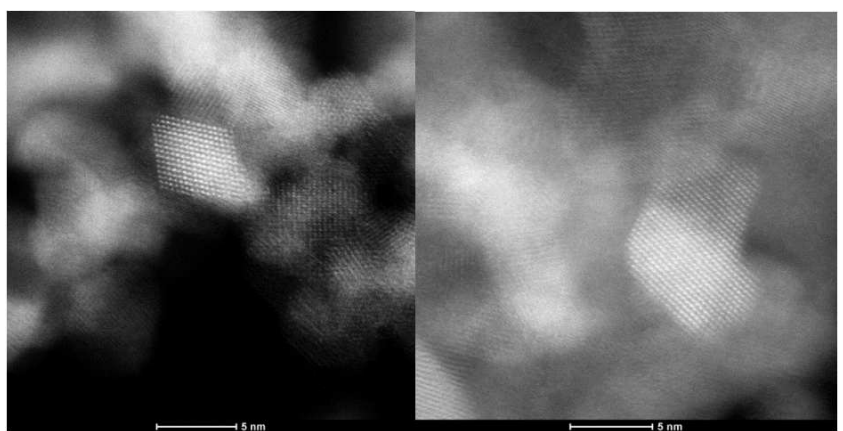

Fig. 6. HAADF image of $\mathrm{CeZrO}_{2}$ (left) and $\mathrm{CeO}_{2}$ (right).

lowed to identify analysed oxide as $\mathrm{CeZrO}_{2}$. Simulation of the unit cell of identified phase in the direction [111] (Fig. 5 (left)) allowed to fit a position of $\mathrm{Ce} / \mathrm{Zr}$ and expected position of $\mathrm{O}$ atoms in the high-resolution image (Fig. 5 (middle))

Figure 6 (left) shows an example of $\mathrm{CeZrO}_{2}$ oxide, and Fig. 6 (right) shows an example of the pure cerium oxide. Performed analysis allowed to determine that the crystals of $\mathrm{CeZrO}_{2}$ have more regular shapes, and their diameter is smaller, and the cerium oxide crystals during the process reached approximately twice the size of $\mathrm{CeZrO}_{2}$ and more irregular shapes.

\section{Conclusions}

For phase analysis of $\mathrm{CeO}_{2}, \mathrm{ZrO}_{2}$, and $\mathrm{CeZrO}_{2}$ crystals deposited on CNT scanning transmission electron microscopy (HAADF imaging), computer simulations and energy dispersive X-ray spectroscopy were applied. Microscopic examination confirmed that distribution of oxides on surface nanotubes is homogeneous. Most of the observed particles have been characterised as $\mathrm{CeZrO}_{2}$ oxide. Some contents of cerium and zirconium oxide suggested not completed the course of the synthesis reaction. Analysed crystals of zirconium-cerium oxide have an average size at about $4-5 \mathrm{~nm}$, and tetragonal lattice. Regular shape of the observed oxides suggests a high potency of the material for catalytic purposes [5].

\section{Acknowledgments}

This publication was financed by the Ministry of Science and Higher Education of Poland as the statutory financial grant of the Faculty of Mechanical Engineering SUT.

\section{References}

[1] P. Serp, M. Corrias, P. Kalck, Appl. Catal. A Gen. 253, 337 (2003).

[2] Y. Zhang, H.B. Zhang, G.D. Lin, P. Chen, Y.Z. Yuan, K.R. Tsai, Appl. Catal. A Gen. 187, 213 (1999).

[3] E.O. Jardim, M. Gonçalves, S. Rico-Francés, A. Sepúlveda-Escribano, J. Silvestre Albero, Appl. Catal. B Environ. 113-114, 72 (2012).

[4] C.-H. Ma, H.-Y. Li, G-D. Lin, H-B. Zhang, Appl. Catal. B Environm. 100, 245 (2010).

[5] C. Wang, B. Li, H. Lin, Y. Yuan, J. Power Sources 202, 200 (2012).

[6] Changqing Li, Nijuan Sun, Jiangfeng Ni, Jinyong Wang, Haibin Chu, Henghui Zhou, Meixian Li, Yan Li, J. Solid State Chem. 18, 2620 (2008).

[7] J.A. Perez-Omil, Ph.D. Thesis, University of Cadiz, Spain 1994.

[8] S. Bernal, F.J. Botana, J.J. Calvino, C. Lopez-Cartes, J.A. Perez-Omil, J.M. Rodriguez-Izquierdo, Ultramicroscopy 72, 135 (1998).

[9] University of Cádiz, Nanomaterials \& Catalysis. 